\title{
THE SOLDIER OF THE ANT CAMPONOTUS (COLOBOPSIS) FRAXINICOLA AS A TROPHIC CASTE*
}

\author{
By Edward O. Wilson \\ Museum of Comparative Zoology Laboratories, \\ Harvard University, Cambridge, Massachusetts 02I38 U.S.A.
}

Complete dimorphism, defined as the coexistence of a minor worker of ordinary proportions with a larger major worker or "soldier," represents the pinnacle of the subcaste system within the ants. The soldier not only weighs more but also possesses a disproportionately larger head. By definition, intermediate forms are lacking. Complete dimorphism has originated independently at least seven times, within the following genera: the myrmicines Pheidole, Oligomyrmex, Acanthomyrmex, Paracryptocerus; the dolichoderine Zatapinoma; and the formicines Camponotus and Pseudolasius. The head shapes of the major workers of these groups are clearly modified either for fighting or for defense of the colony by blocking the nest entrances. These functions have been confirmed by direct observations of colonies of Pheidole, Paracryptocerus, and Camponotus (Wilson, I97 I). The behavioral repertory of the major workers is otherwise very limited in comparison with that of the minor workers, giving logic to their alternate designation in the literature as soldiers.

The principal purpose of this article is to demonstrate that in at least one species, Camponotus (Colobopsis) fraxinicola M. R. Smith, the soldier caste also plays a key role in liquid food storage.

\section{Materials AND Methods}

Colonies were collected at St. Mark's Lighthouse and Tall Timbers, near Tallahassee, Florida. The taxonomic identification requires a brief note. Three forms of the southeastern United States, fraxinicola, impressus, and pylartes, are very similar to each other and may prove synonymous. The Tallahassee series fall closest to fraxinicola in the seemingly best character states of the major worker: a slightly more flattened mesonotum, more rounded posterior rim of the truncated portion of the head, and in other, more subtle details of head shape. But all of these characters vary widely within and among series from widespread localities, so that eventually only one

\footnotetext{
*Manuscript received by the editor February 28, 1974.
} 
species might be recognizable, which would then take the name impressus.

The colonies were transferred to glass tubes $15 \mathrm{~cm}$ in length and 3-6 $\mathrm{mm}$ in inner diameter. The tubes were each plugged at one end with dry wads of cotton wool and placed in open plastic containers, the inner sides of which were lined with fluon to discourage climbing by the ants. Since the latter method does not always work with these highly arboreal ants, the containers were also supported by glass bottles set in petri dishes filled with heavy mineral oil. Water was made available in moistened cotton plugs at the bottom of test tubes placed next to the tubes housing the colonies. The ants were fed daily with honey and freshly killed insects. Entire colonies quickly habituated to strong light. They could be observed in toto with a swing-arm dissecting microscope without being disturbed in their new, highly simplified (and fluon-lined) universe.

\section{The Soldier as a Defensive Caste}

Since the time of Forel ( 1874 ) it has been known that soldiers of the subgenus Colobopsis of Camponotus use their oddly cylindrical heads to block the nest entrances. Minor workers returning from foraging trips identify themselves to the soldiers, presumably by colony odor. The soldiers then pull back to let them enter. C. fraxinicola, like most other Colobopsis, nest in the cavities of dead twigs. The nest entrances are neat, circular holes into which the heads of the soldiers fit snugly. By plugging glass tubes containing colonies with disks of cork, I was able to observe the excavation of the nest entrances on repeated occasions. The task was performed exclusively by the minor workers. This is somewhat surprising in view of the fact that the holes are cut to fit the specifications of the soldiers and not those of the minor workers. The soldiers also rested more consistently near the entrances of the glass tubes, with their heads pointing outward in a high proportion of cases, even when they were not actively engaged in blocking the entrances.

Undecane, stored in Dufour's gland of the abdomen, is a general formicine alarm pheromone (Wilson and Regnier, 1971). When small quantities of this substance were allowed to evaporate near the nest entrance, all members of the fraxinicola colonies were thrown into the typical excited running movements of the fraxinicola alarm response. But some of the soldiers moved to the nest entrances, filling those holes still unplugged at the start of the alarm reaction. 


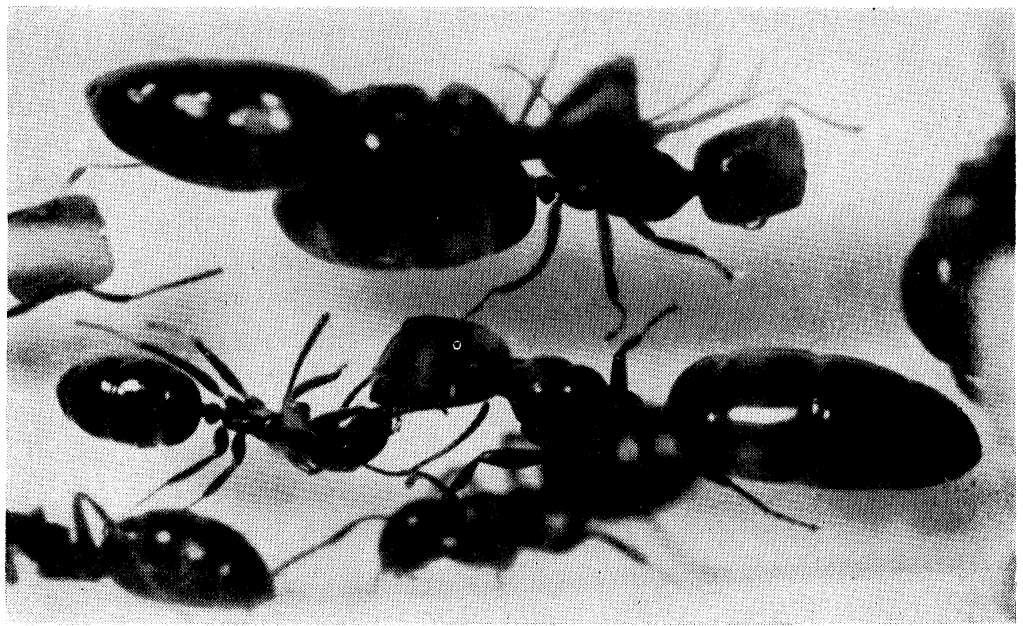

Figure 1. Portion of a laboratory colony of Camponotus (Colobopsis) fraxinicola housed in a glass tube. The large soldiers use their cylindrical heads to block the circular nest entrances, which are cut by the minor workers. This colony has been fed ad libitum, and consequently both soldiers and minor workers are in replete condition. In the center, a soldier and minor worker exchange food by regurgitation.

When twigs containing fraxinicola colonies are first broken open, both minor workers and soldiers rush out. Many attack any accessible alien object, such as the observer's hand or a bit of cloth offered to them, biting it and spraying it with formic acid. The same response was obtained in the laboratory by permitting fire ant workers (Solenopsis invicta) to invade the nests. Individuals of both castes were about equally aggressive and effective in repelling these invaders. On the other hand, the total population of minor workers, by virtue of its greater size, was more effective than that of the soldiers.

To sum up the results, the fraxinicola soldiers are indeed a defensive caste, but their specialization makes them superior in only one aspect of this role.

\section{The Soldier as a Trophic Caste}

The fraxinicola major worker is also anatomically distinguished by its proportionately larger abdomen. All individuals dissected from two laboratory colonies had large fat bodies and well developed ovaries containing one to seven eggs, some of which were of very 
large size. A few minor workers with distended abdomens taken from within the nest had similar abdominal contents, but the majority from both within and outside the nest had proportionately much smaller fat bodies and reduced ovaries. Thus the soldiers store substantially more food in the form of fat than do the minors. The nature of their eggs has not been ascertained. Should they prove to be trophic eggs, this form of storage would be primarily the province of the soldier caste.

The following data reveal that the soldiers also store disproportionately large quantities of liquid food in their crops. When colonies are fed ad libitum with saturated sucrose solution or honey, most of the workers in both subcastes become repletes. Repletism has been defined for purposes of this analysis as distention of the abdomen to the extent that the intersegmented membranes are exposed, permitting the interior of the crop to be seen when light is transmitted from below. It has been repeatedly observed in our laboratory colonies that a higher proportion of the major workers - sometimes all of them - become repletes when the colony is offered a superabundance of liquid food. But when the colony is starved, the proportion of repletes among the majors drops below that of the minors. Two examples are presented in Figure 2.

The amount of liquid stored by each major is substantially greater than that stored by each minor, on both an absolute and per-unitweight basis. This difference, which was first guessed by simple inspection, was proved by the following series of measurements. Twenty minors and I I majors were selected at random and weighed from a colony anesthetized after two weeks of starvation. Then the colony was fed to satiety over a 24-hour period and anesthetized again; 20 minors and 16 majors were next selected at random from among the replete individuals and weighed. The mean weight of the starved minors was I.62 mg (range $1.29-2.42 \mathrm{mg}$ ); after feeding, their mean weight was $2.44 \mathrm{mg}$ ( range $1.75-3.33 \mathrm{mg}$ ), a gain of $0.82 \mathrm{mg}$ or 50.6 percent. The mean weight of the starved majors was $3.44 \mathrm{mg}$ (range 2.38-4.65 mg); after feeding, their mean weight was 5.62 $\mathrm{mg}(3.14-7.34 \mathrm{mg})$, a gain of $2.18 \mathrm{mg}$ or 63.4 percent.

The disparity in storage capacity can be seen even more clearly by examining the colony as a whole. The colony labelled No. I in Figure 2 can be taken as typical; it contained I 39 minors, 26 majors, and a single queen. Using the data on weight gain and percentage of repletism during a single experimental run, the following storage capacities were estimated: the entire minor population stored 88.52 

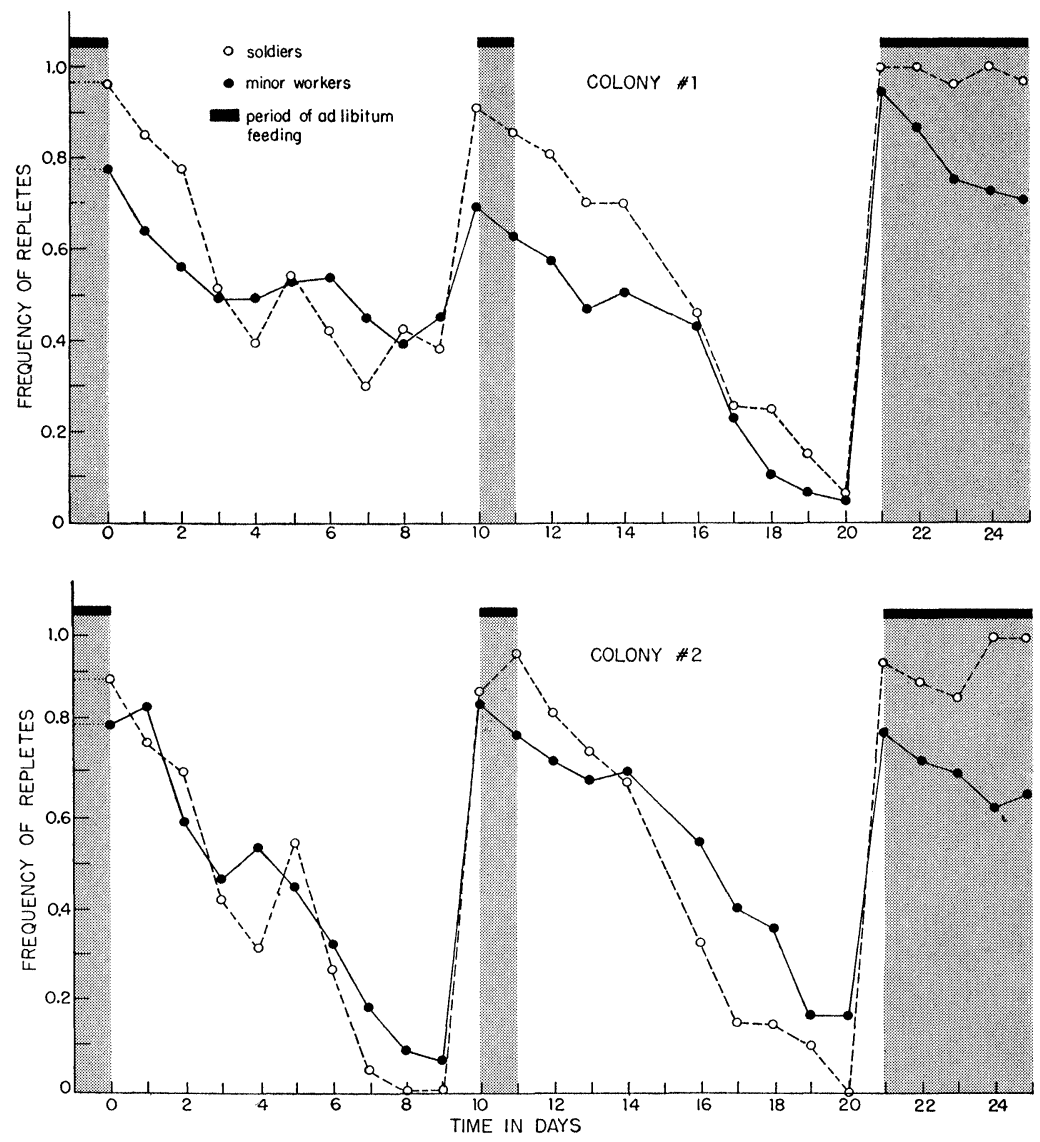

Figure 2. The frequency of repletes among the soldiers and the minor workers respectively in two colonies of Camponotus (Colobopsis) fraxinicola. The ants were fed to satiation with sucrose solution on three occasions ten days apart and starved in the intervening periods. The soldier caste consistently achieved a higher level of repletion when the colony was fed but surrendered it to a greater extent when the colony was starved. 
$\mathrm{mg}$, and the entire major population stored $54.59 \mathrm{mg}$. Thus although the majors made up a little less than 16 percent of the population and contained 28.43 percent of the wet weight in the non-replete condition, they stored 38.15 percent of the liquid at repletion.

A distinctive history of liquid flow unfolds when a colony discovers a single rich source of food and then endures a period of starvation - the circumstance simulated by the laboratory experiments. When the food is first discovered, the flow during the first one or two hours is from the foraging minor workers to other minors and majors encountered back at the nest. After saturation is attained, and 90 percent or more of the adults are replete, regurgitation continues at a high rate. The two castes participate at about the same per-worker rate, with no apparent difference between the majors and minors in the frequency of donation as opposed to that of reception. Within 2-3 days after the food is cut off, majors have begun to feed minors larger quantities than they receive. Data on exchanges show that the major-to-major donations are fewer than would be expected by chance alone. This is due at least in part to the fact that the majors are relatively sluggish in their movements. The minors are much the more active caste, passing from one nestmate to another to collect and pass along the dwindling supply of liquid food.

\section{Acknowledgement}

This article is part of a continuing study on caste systems supported by Grant Number GB-40247 from the National Science Foundation.

\section{SumMary}

( I) The major worker, or "soldier," of Camponotus (Colobopsis) fraxinicola, helps to defend the nest by blocking the entrance holes with its head, a behavior pattern reported by previous authors in other members of the genus. However, when the nest is breached and combat ensues, the soldier is no more aggressive or effective than the minor worker.

(2) The nest entrances are constructed entirely by the minor workers, which cut them to fit the cylindrical heads of the majors.

(3) Major workers respond to undecane, a general formicine alarm substance, by moving to block those nest entrances still open at the beginning of the episode. 
(4) Major workers also serve as a storage caste. Their abdomens are partially filled with exceptionally large fat bodies. They also store a disproportionate share of sugary liquids collected by the colony. When this food is superabundant, the majors reach a higher level of repletion. When the colony is subsequently starved, the majors regurgitate the liquid back to the rest of the colony faster than they receive it.

\section{Literature Cited}

FOREL, A.

1874. Les fourmis de la Suisse. Société Helvétique des Sciences Naturelles, Zurich. iv $+452 \mathrm{pp}$.

WILSON, E. O.

1971. The insect societies. Belknap Press of Harvard University Press. $\mathrm{x}+548 \mathrm{pp}$.

Wilson, E. O. and F. E. Regnier.

1971. The evolution of the alarm-defense system in the formicine ants. American Naturalist, 105: 279-289. 

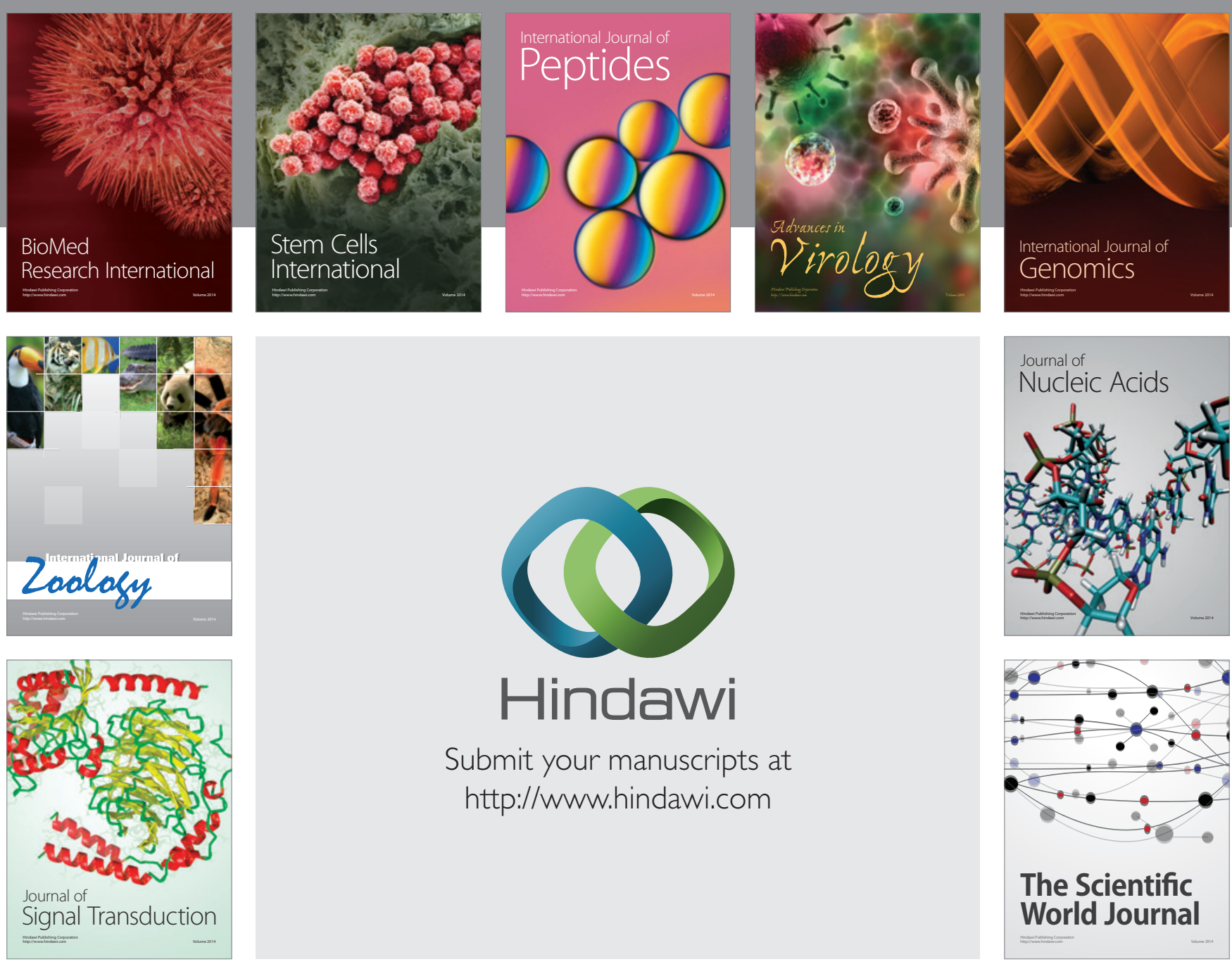

Submit your manuscripts at

http://www.hindawi.com
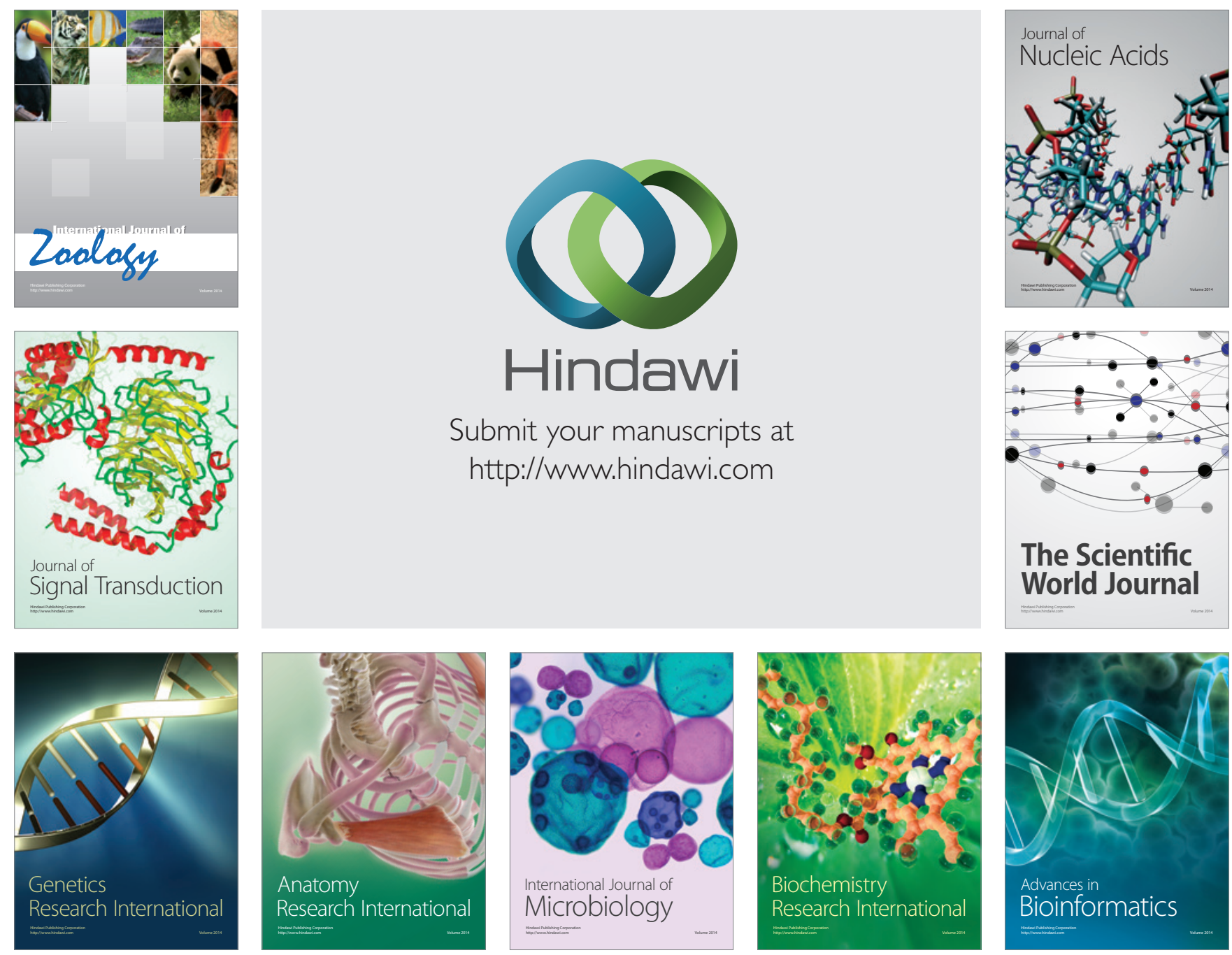

The Scientific World Journal
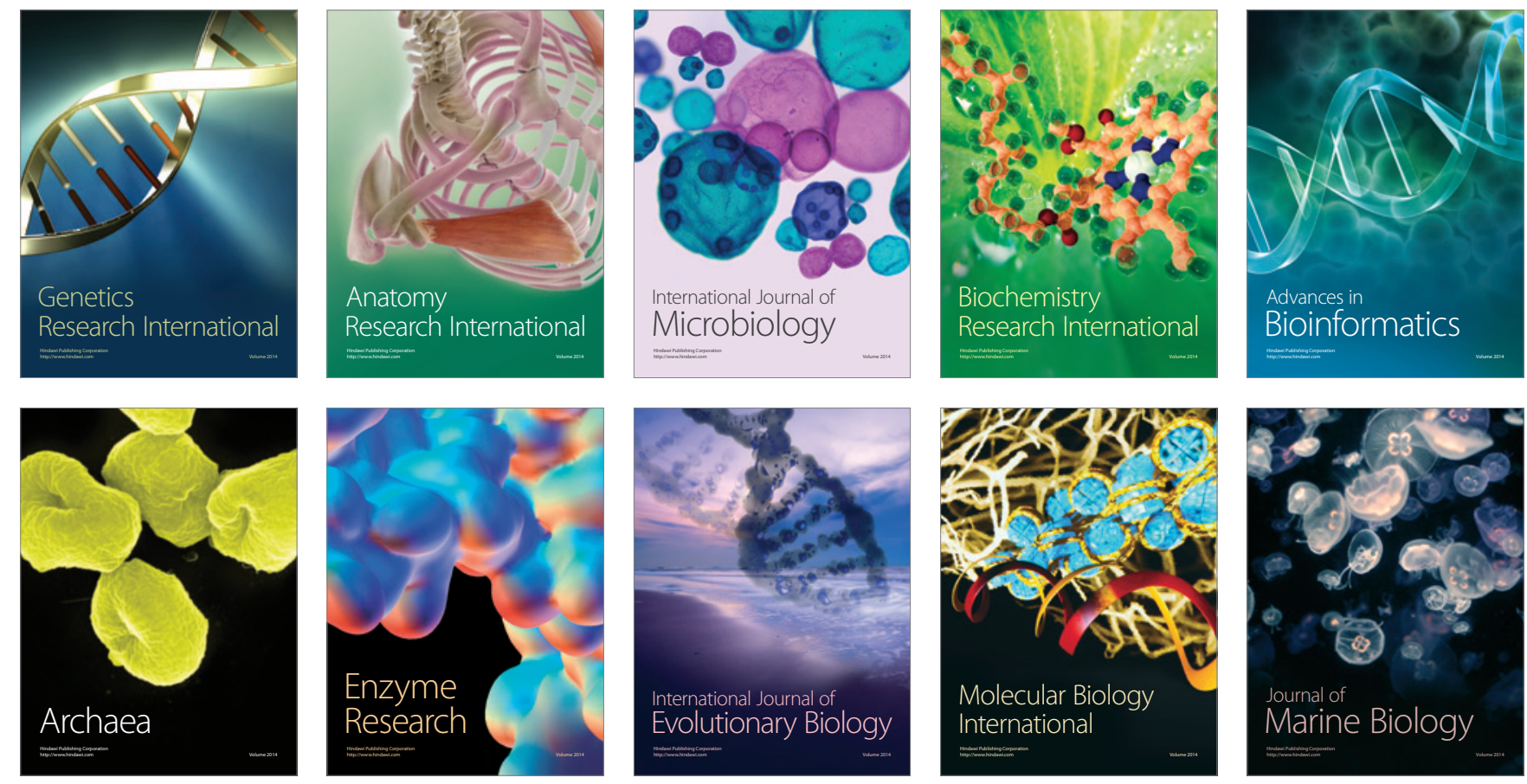